\title{
Studi Pemisahan Bitumen dari Asbuton Menggunakan Media Air Panas dengan Penambahan Surfaktan Anionik dan $\mathrm{NaOH}$
}

\author{
Susianto, Yosita Dyah Anindita, Gissa Navira Sevie, Fadlilatul Taufany \& Ali Altway \\ Dosen, Teknik Kimia, Fakultas Teknologi Industri, ITS \\ Mahasiswa, Teknik Kimia, Fakultas Teknologi Industri, ITS \\ aninditayosita@gmail.com
}

\begin{abstract}
Abstrak
Asbuton adalah aspal alam yang terkandung dalam deposit batuan terdapat di Pulau Buton, Sulawesi Tenggara. Asbuton dimanfaatkan sebagai bahan alternatif pengganti aspal minyak setelah bitumen dipisahkan dari mineralnya. Penelitian proses pemisahan bitumen dari asbuton menggunakan hot water process sebelumnya telah dilakukan, tetapi bitumen yang terambil kurang maksimal. Oleh karena itu, pada penelitian ini bertujuan untuk meningkatkan \% recovery bitumen dengan modifikasi hot water process melalui penambahan surfaktan anionik dan $\mathrm{NaOH}$. Proses pemisahan bitumen dari asbuton dilakukan melalui dua proses utama, yakni premixing-preheating dan digesting. Premixing-preheating dilakukan dengan mengaduk $250 \mathrm{rpm}$ asbuton dan solar pada suhu $60,70,80$, dan $90^{\circ} \mathrm{C}$ selama 30 menit. Proses digesting mengaduk $1500 \mathrm{rpm}$ campuran solar-asbuton dengan penambahan wetting agent (Rwa), berupa larutan surfaktan LAS-NaOH sebesar 25\%,30\%,35\% dan 40\% terhadap massa campuran total. Konsentrasi larutan surfaktan LAS sebesar 0,5\%,1\%,1,5\% dan 2\%. Produk proses digesting dipisahkan secara gravitasi dengan menambahkan air garam konsentrasi $3.5 \%$ sehingga terbentuk tiga lapisan. Lapisan teratas merupakan larutan bitumen-solar, ditimbang berat dan diukur densitasnya untuk mengetahui persen (\%) recovery yang diperoleh. Hasil penelitian menunjukkan bahwa \% recovery bitumen tertinggi diperoleh sebesar $97,74 \%$ pada suhu $90^{\circ} \mathrm{C}$ dengan wetting agent $25 \%$ dan konsentrasi surfaktan $1.5 \%$.
\end{abstract}

Kata kunci: asbuton, hot water process, surfaktan anionik, $\mathrm{NaOH}$

\section{PENDAhuluan}

Kebutuhan aspal Indonesia mencapai 1,2 juta ton per tahun. Dari kebutuhan aspal ini, produsen aspal Indonesia hanya mampu memenuhi 900.000 ton per tahun, atau setara dengan 75\% kebutuhan nasional. Sehingga untuk memenuhi kebutuhan nasional tersebut pemerintah melakukan impor sekitar 300.000 ton per tahunnya.

Aspal minyak sangat bergantung dengan ketersediaan minyak bumi dan hanya minyak bumi yang memiliki kandungan aspalten tinggi yang mengandung bitumen sehingga tidak semua minyak bumi mengandung bitumen. Oleh karena itu harus ada usaha alternatif lain yaitu aspal alam. Hal ini didasarkan Indonesia negara yang memiliki aspal alam kaya bitumen terbesar di dunia, yakni di Pulau Buton, Provinsi Sulawesi Tenggara. Aspal alam ini seringkali disebut Asbuton (aspal batu buton), karena bitumen yang ada membungkus partikel batuan kalsium, sehingga aspal alam ini cepat mengeras seperti batu. Menurut Departemen Pekerjaan Umum (2006), total cadangan asbuton mencapai 677.247.000 ton atau setara dengan 170.000.000 diproyeksi mampu memenuhi kebutuhan aspal nasional selama 330 tahun. Kadar aspal yang terkandung dalam Asbuton bervariasi, antara $20-30 \%$.

Dalam lingkup penelitian berbagai metode digunakan untuk memisahkan bitumen dari asbuton, yakni metode solvent recovery. Pada metode ini digunakan pelarut hidrokarbon dan turunannya yang bersifat nonpolar seperti, n-heksana [1], TCE (trichloroethylene) dan n-propil bromida, karbon tetraklorida (CCl4)[2], Pertasol [3], Kerosin[4] dan Solar [5], diperoleh hasil bahwa dibutuhkan pelarut organik dalam jumlah besar untuk mendapatkan bitumen dari asbuton sehingga kurang ekonomis. Sehingga pemisahan bitumen dari asbuton menggunakan metode solvent recovery tidak berhasil diterapkan dalam skala industri karena diperkirakan menelan biaya operasi yang cenderung tinggi. Proses yang kedua yaitu metode pemisahan dengan menggunakan media air panas yang pertama kali dilakukan oleh Clark pada tahun 1920 untuk memisahkan bitumen pada Athabasca oil sand. Metode pemisahan dengan menggunakan media air panas merupakan pemisahan bitumen melalui injeksi air panas dan bahan kimia seperti pelarut nonpolar terhadap oil sand. Metode ini cukup efektif untuk memisahkan bitumen dari oil sand [6]. Proses ini pada dasarnya bisa diaplikasikan untuk memisahkan bitumen dari asbuton, walaupun jenis pengotor yang terkandung dalam oil sand dan asbuton berbeda. Pengotor pada oil sand berupa silika ( $\left.\mathrm{SiO}_{2}\right)$ [7], sedangkan pada Asbuton terkandung banyak kalsium karbonat $\left(\mathrm{CaCO}_{3}\right)$ menurut Departemen Pekerjaan Umum, (2006) [8]. Proses ini dapat digunakan untuk memisahkan bitumen dari asbuton adalah karena air panas mampu menurunkan tegangan permukaan pada asbuton sedangkan pelarut non polar mampu menarik bitumen (karena sama-sama bersifat non polar) sehingga diperkirakan bitumen dapat dipisahkan dari berbagai pengotor yang terkandung di dalam asbuton. Namun yang perlu diperhatikan proses air panas ini tidak dapat diaplikasikan langsung, karena $\mathrm{CaCO}_{3}$ memiliki angka kelarutan yang lebih tinggi dibanding $\mathrm{SiO}_{2}$ di dalam air sehingga perlu dilakukan modifikasi pada proses air panas. Beberapa modifikasi proses air panas yang dilakukan adalah dengan menambahkan surfaktan serta $\mathrm{NaOH}$. Surfaktan dan $\mathrm{NaOH}$ berfungsi sebagai 
penurun tegangan permukaan antara bitumen dan pengotor yang berupa padatan sehingga menyebabkan bitumen bisa bergabung dengan pelarut non polar. Selain itu $\mathrm{NaOH}$ juga berfungsi sebagai sealing agent yang menjadi seal antara lapisan solar-aspal dengan lapisan batuan sehingga kedua lapisan tidak bercampur [9].

Salah satu problematika yang dihadapi pada media air panas dengan modifikasi untuk memisahkan bitumen dari asbuton adalah $\%$ recovery yang kurang sempurna. Penggunaan jenis surfaktan yang kurang tepat dimungkinkan menjadi penyebab masih kurang sempurnanya \% recovery bitumen dari asbuton. Surfaktan memiliki peranan penting dalam pemisahan bitumen menggunakan media air panas karena dapat menurunkan tegangan permukaan antara bitumen dengan mineral yang terkandung dalam asbuton yang mengakibat lapisan bitumen-solar yang tadinya terperangkap dalam mineral mampu terangkat ke permukaan. Hal tersebut memotivasi kami untuk melakukan penelitian yang mempelajari pengaruh surfaktan anionik terhadap proses pemisahan bitumen dengan media air panas untuk mendapatkan \% recovery yang lebih tinggi.

\section{TINJAUAN PUSTAKA}

Bitumen merupakan hidrokarbon rantai panjang yang ditemukan dalam bentuk cairan sangat kental ataupun padatan pada suhu kamar $\left(25^{\circ} \mathrm{C}\right)$, berwarna hitam, dan menunjukkan sifat thermoplastic, yakni menjadi encer ketika dipanaskan, namun kembali mengeras seiring dengan pendinginan. Bitumen tergolong perekat dan waterproofing agent yang baik, dan memiliki ketahanan yang baik terhadap reaksi oksidasi. Walaupun demikian, bitumen mudah larut dalam berbagai pelarut organik seperti benzena, trikloroetana, dan karbon disulfida.

Bitumen ditemukan pada sejumlah deposit di permukaan bumi. Deposit ini terbentuk akibat adanya minyak bumi yang terdorong menembus kerak bumi. Komponen yang mudah menguap dari minyak bumi, seperti gasoline, kerosene menguap dan meninggalkan sejumlah deposit bitumen yang tercampur dengan mineral anorganik. Campuran bitumen-mineral anorganik inilah yang kemudian disebut sebagai aspal alam.

Asbuton adalah aspal alam yang terdapat di pulau Buton, Sulawesi Tenggara. Asbuton pada umumnya berbentuk padat yang terbentuk secara alami akibat proses geologi. Proses terbentuknya asbuton berasal dari minyak bumi yang terdorong muncul ke permukaan menyusup di antara batuan yang berpori. Berdasarkan data Departemen Pekerjaan Umum (2006), Asbuton (Aspal Batu Buton) yang ditemukan kira-kira 70 tahun yang lalu merupakan deposit aspal alam terbesar di dunia.

Menurut Cullum (1994), surfaktan (surface active agent) merupakan suatu zat yang memiliki kemampuan menurunkan tegangan permukaan (interfacial tension). Salah satu sebabnya adalah karena surfaktan memiliki gugus hidrofilik (bagian polar) di satu sisi dan hidrofobik (non-polar) di sisi yang lain. Bagian polar surfaktan dapat bermuatan positive, negative atau netral. Pada sebagian besar surfaktan, bagian hidrofobiknya berupa rantai hidrokarbon yang memiliki panjang rantai 12 hingga 18 atom karbon dan disebut juga sebagai ekor, sementara bagian yang polar disebut sebagai kepala. Sifat hidrofob dan hidrofil dari surfaktan dapat dilihat dari nilai Hidrophile Lipophile Balance (HLB) dari surfaktan tersebut, semakin tinggi nilai HLB suatu surfaktan akan lebih bersifat hidrofil sedangkan semakin rendah nilai HLB suatu surfaktan akan lebih bersifat hidrofob.

Penambahan surfaktan dalam larutan akan menyebabkan turunnya tegangan permukaan larutan. Setelah mencapai konsentrasi tertentu, tegangan permukaan akan konstan walaupun konsentrasi surfaktan ditingkatkan. Bila surfaktan ditambahkan melebihi konsentrasi ini maka surfaktan mengagregasi membentuk misel. Konsentrasi terbentuknya misel ini disebut Critical Micelle Concentration $(C M C)$. Tegangan permukaan akan menurun hingga CMC tercapai. Setelah CMC tercapai, tegangan permukaan akan konstan yang menunjukkan bahwa antar muka menjadi jenuh dan terbentuk micelle yang berada dalam keseimbangan dinamis dengan monomer Micelle tersebut adalah pengumpulan atau agregasi molekul molekul surfaktan.

Salah satu jenis surfaktan yang sering digunakan untuk pemisahan bitumen adalah surfaktan anionik. Menurut Genaro (1990), Sodium Dodecyl Benzene Sulfonate (LAS) adalah surfaktan anionik umumnya sebagai pembasah, foaming, emulgator dalam pembuatan detergen. LAS terbentuk dari reaksi antara Benzene dan Dodecene membentuk Dodecyl Benzene. Kemudian Dodecyl Benzene yang terjadi ditambahkan dengan oleum menghasilkan Dodecyl Benzene Sulfonic Acid. Dodecyl Benzene Sulfonic Acid yang terjadi kemudian dinetralkan dengan penambahan NaOH sehingga menghasilkan Sodium Dodecyl Benzene Sulfonate. LAS memiliki rantai hidrokarbon sebagai gugus hidrofobik dan ion $\mathrm{SO}^{3-} \mathrm{sebagai}^{3} \mathrm{gug}$ hidrofiliknya.

\section{METODE PENELITIAN}

Proses pelarutan bitumen aspal dilakukan didalam suatu tangki digester dengan diameter 10,8 cm dan tinggi $20 \mathrm{~cm}$, pada tangki juga dipasang baffle untuk mengurangi terjadinya vortex didalam tangki tersebut dipasang thermocouple sebagai alat pembaca temperatur. Tangki digester ini dilengkapi dengan impeller jenis disk turbine untuk proses pencampuran dimana putaran impeller tersebut diatur menggunakan pengatur putaran. Pada bagian luar tangki terdapat waterbath yang dilengkapi dengan pengatur temperatur berfungsi sebagai media pemanas.

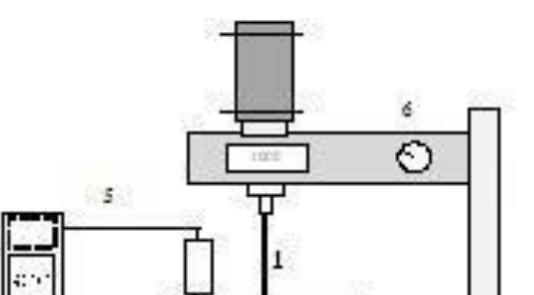




\author{
Keterangan Gambar : \\ 1. Pengaduk \\ 2. Tangki Digester \\ 3. Baffle \\ 4. Waterbath \\ 5. Thermocouple \\ 6. Pengatur Putaran \\ 7. Pengatur suhu
}

Gambar 1. Tangki Digester

Proses pemisahan bitumen dari batuan asbuton digunakan bantuan air panas, dengan adanya air panas diharapkan bitumen yang terdapat pada batuan asbuton semakin mudah terlarut. Surfaktan LAS ditambahkan untuk menurunkan tegangan permukaan, sehingga efek pembasahan (wetting) dapat terjadi dan membuat bitumen mudah terlarut dalam solar. Selain itu juga ditambah $\mathrm{NaOH}$ yang berfungsi sebagai sealing agent, yang berfungsi sebagai seal agar lapisan lumpur ridak bercampur kembali dengan lapisan bitumen-solar. Kadar bitumen dalam asbuton dianalisis melalui metode ekstraksi menggunakan soklet sesuai SNI 03-3640-1994 (BALITBANG-DINAS PU) menggunakan pelarut Trichloroethylene. Pada tahap analisis kadar bitumen hasil penelitian dilakukan dua pengukuran, pengukuran berat lapisan atas yang berupa lapisan bitumen-solar dan pengukuran densitas lapisan atas. Menggunakan bantuan kurva kalibrasi hubungan antara $1 / \rho$ dan $\%$ konsentrasi bitumen dalam solar untuk menentukan \% konsentrasi bitumen larutan hasil percobaan.

\section{HASIL DAN PEMBAHASAN}

Proses pemisahan bitumen dari aspal alam seperti asbuton menggunakan metode hot water terdiri dari tiga tahapan proses, yakni proses premixing-preheating, digesting dan proses pemurnian bitumen. Namun proses digesting dianggap lebih menentukan (Miller, 1991), sehingga perlu dilakukan penelitian lebih lanjut mengenai variabel-variabel yang mempengaruhinya. Asbuton merupakan aspal alam dengan viskositas sebesar 154 poise [10], dengan viskositas bitumen antara 5-1000 poise tergolong dalam Tar Sand kelas III yang membutuhkan diluent untuk meningkatkan \% recovery bitumen. Diluent yang ditambahkan untuk menurunkan viskositas dari asbuton sehingga bisa membantu efektivitas dari proses digesting hot water ini. Pada penelitian ini digunakan 3 macam diluent, yakni solar sebagai penetrating agent, surfaktan Linear Alkylbenzene Sulfonate (LAS) sebagai wetting agent, dan Sodium Hidroksida sebagai sealing agent.

Pada proses pertama, solar dan asbuton mengalami tahapan mixing dan preheating menggunakan pengadukan $250 \mathrm{rpm}$ selama 30 menit, kemudian tahapan digesting dilakukan pada kecepatan pengadukan 1500 rpm dengan waktu pengadukan selama 30 menit. Variabel yang digunakan pada penelitian ini menggunakan konsentrasi surfaktan Linear Alkylbenzene Sulfonate (LAS), Penambahan larutan surfaktan- $\mathrm{NaOH}\left(\mathrm{R}_{\mathrm{wa}}\right)$ dan perubahan temperatur.

Pengaruh konsentrasi surfaktan LAS terhadap perolehan \% recovery bitumen ditunjukkan pada Gambar 2, yakni grafik konsentrasi surfaktan LAS (\% massa) terhadap \% recovery bitumen pada konsentrasi $\mathrm{NaOH} 1 \%$ dalam berbagai nilai $\mathrm{R}_{\text {wa. }}$

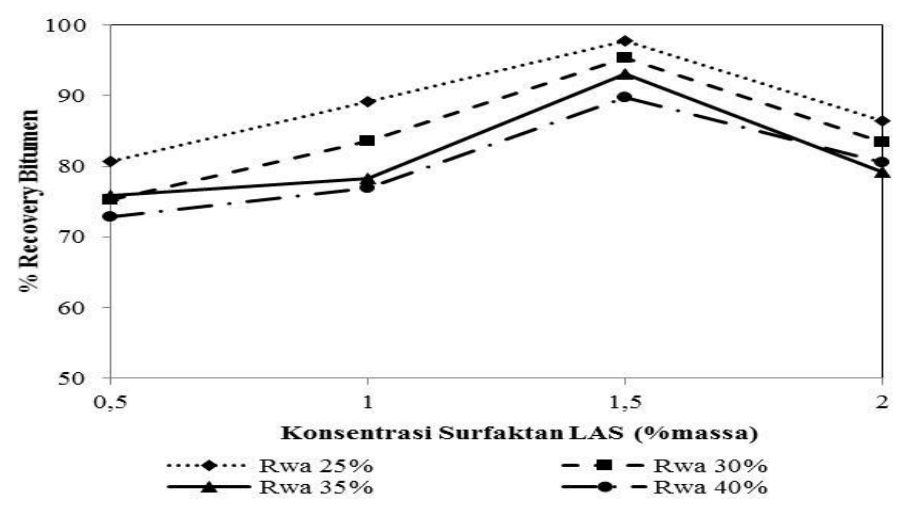

Gambar 2. Pengaruh konsentrasi surfaktan LAS terhadap \% recovery bitumen pada Rs (Rasio solar :asbuton) $60 \%$ dan konsentrasi $\mathrm{NaOH}$ $1 \%$

Gambar 2 menunjukkan bahwa konsentrasi surfaktan LAS 1,5\% merupakan konsentrasi yang optimal untuk menghasilkan \% recovery bitumen tertinggi. Hal ini dikarenakan pada konsentrasi surfaktan LAS 1,5\% lapisan bitumen-solar terpisahkan secara sempurna dari lapisan mineral. Sementara konsentrasi surfaktan LAS di bawah 1,5\% belum mampu menurunkan interfacial tension antara lapisan bitumen-solar dengan lapisan mineral secara sempurna sehingga masih 
adacampuran bitumen-solar yang terikut pada lapisan mineral. Sedangkan pada konsentrasi surfaktan LAS di atas $1,5 \%$ menyebabkan lapisan mineral turun viskositasnya sehingga mudah bercampur dengan lapisan bitumen-solar membentuk lapisan homogen yang susah dipisahkan. Hal inilah yang menyebabkan semakin tinggi konsentrasi surfaktan dapat menyebabkan turunnya \% recovery bitumen. Penurunan \% recovery bitumen juga diakibatkan karena konsentrasi surfaktan LAS melewati titik CMC (Critical Micelle Concentration) nya.

Linear Alkylbenzene Sulphonate yang bersifat water base dipilih sebagai wetting agent dikarenakan dapat meminimalisir emulsi yang terjadi antara lapisan air dengan lapisan bitumen-solar dan mampu mengikat lapisan mineral (Audibert-Hayet, 2006) sehingga lapisan bitumen-solar yang diperoleh bisa terpisah sempurna dari lapisan mineral

Dari penelitian mengenai pengaruh konsentarsi surfaktan LAS terhadap \% recovery didapatkan konsentrasi surfaktan LAS optimal pada $1,5 \%$ massa yang mampu menghasilkan \% recovery sebesar $97,74 \%$ yakni pada nilai $\mathrm{konsentrasi} \mathrm{NaOH}$ $1 \%$ dan nilai $\mathrm{R}_{\text {wa }}$ sebesar $25 \%$.

Pengaruh temperatur terhadap perolehan \% recovery bitumen ditunjukkan pada Gambar 3, yakni grafik temperatur terhadap \% recovery bitumen. Pada konsentrasi surfaktan LAS 1,5\% dan konsentrasi $\mathrm{NaOH} 1 \%$ dalam berbagai Penambahan larutan surfaktan- $\mathrm{NaOH}\left(\mathrm{R}_{\mathrm{wa}}\right)$.

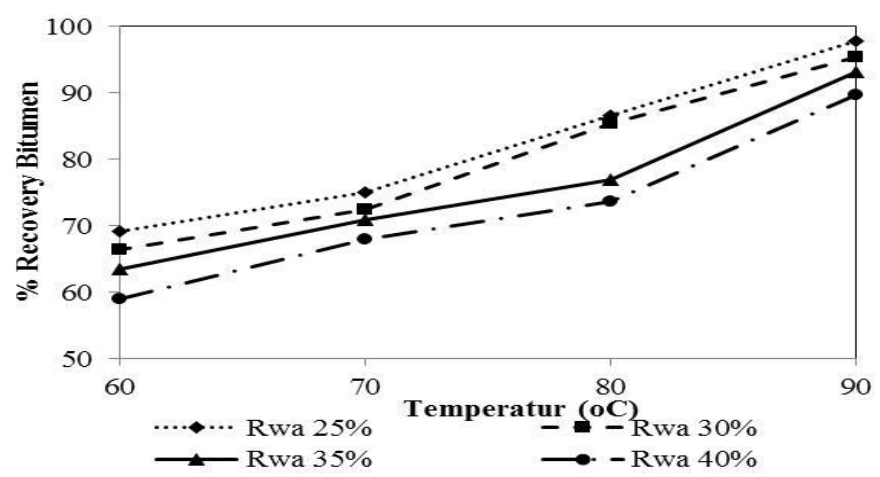

Gambar 3. Pengaruh temperatur terhadap \% recovery bitumen pada konsentrasi surfaktan LAS 1,5\% dan konsentrasi $\mathrm{NaOH} 1 \%$

Gambar 3 menunjukkan bahwa semakin tinggi suhu maka \% Recovery yang diperoleh semakin tinggi. Hal tersebut disebabkan karena semakin tinggi temperatur yang digunakan pada Hot Water Process maka viskositas dan interficial tension akan semakin turun sehingga kinerja surfaktan LAS menjadi optimal, bitumen akan lebih mudah terlepas dari asbuton (Miller,1991). Bitumen yang sebagian telah larut pada proses pencampuran solar dan asbuton, viskositas dan ukuran partikelnya menjadi semakin kecil oleh pemanasan serta dibantu dengan proses pengadukan menyebabkan bitumen lebih mudah dipisahkan dari asbuton.

Pengaruh besar nilai Rwa terhadap perolehan \% Recovery bitumen dengan Rs 60\%, konsentrasi $\mathrm{NaOH} 1 \%$ dan temperatur $90^{\circ} \mathrm{C}$ dengan berbagai nilai konsentrasi surfaktan LAS dapat ditunjukkan pada Gambar 4

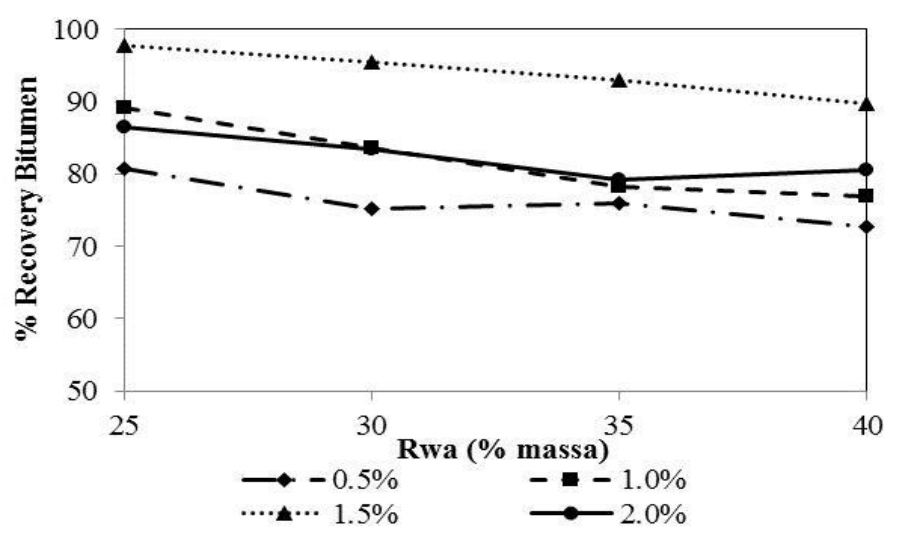

Gambar 4. Pengaruh penambahan surfaktan LAS dan $\mathrm{NaOH}$ (Rwa) terhadap \% recovery bitumen pada Rs $60 \%$, konsentrasi NaOH $1 \%$ dan temperatur $90{ }^{\circ} \mathrm{C}$ dengan berbagai nilai konsentrasi surfaktan LAS

Gambar 4 menunjukkan bahwa \% Recovery bitumen cenderung menurun dengan meningkatnya nilai Rwa diatas $25 \%$. Rasio larutan surfaktan LAS-NaOH: larutan total (Rwa) yang terlalu besar dapat menyebabkan terlalu eksesnya jumlah partikel dari surfaktan LAS dan $\mathrm{NaOH}$ sehingga meningkatkan hidrolisis mineral (keterbasahan) menyebabkan mineral bercampur dengan campuran bitumen-solar. Hal ini bisa menyebabkan dua hal, pertama mineral terikut bersama lapisan atas (bitumen-solar) dengan membentuk lapisan bitumen-solar-mineral yang homogen sehingga sulit dipisahkan, atau sebagian lapisan atas (solar-aspal) terikut bersama mineral di lapisan bawah.

Dari penelitian mengenai variabel rasio larutan surfaktan LAS-NaOH : larutan total (Rwa) didapatkan bahwa \% Recovery bitumen tertinggi, yakni sebesar $97,74 \%$ yang dihasilkan pada nilai Rwa $25 \%$, temperatur $90^{\circ} \mathrm{C}$ dan konsentrasi surfaktan LAS 1,5\%. 


\section{KESIMPULAN}

Temperatur berbanding lurus dengan \% recovery Bitumen dengan temperatur terbaik pada $90{ }^{\circ} \mathrm{C}$ dan $\%$ recovery optimum diperoleh pada kosentrasi surfaktan LAS 1,5\% yaitu sebesar 97,74\% dengan larutan surfaktan LAS-NaOH : larutan total $25 \%$ dan konsentrasi $\mathrm{NaOH} 1 \%$. \% Recovery bitumen meningkat seiring dengan meningkatnya konsentrasi surfaktan LAS dari 80,67\% pada konsentrasi surfaktan LAS 0,5\% hingga 97,74\% pada konsentrasi surfaktan LAS 1,5\%, kemudian mengalami penurunan hingga $88,59 \%$ pada konsentrasi surfaktan $2 \%$ dengan temperatur $90^{\circ} \mathrm{C}$, dan Rwa sebesar $25 \%$. \% Recovery bitumen menurun seiring dengan meningkatnya penambahan wetting agent (Rwa) dari 97,74\% pada nilai Rwa sebesar $25 \%$ menjadi $89,74 \%$ pada nilai Rwa sebesar $40 \%$ dengan temperatur $90^{\circ} \mathrm{C}$ dan konsentrasi surfaktan LAS $1,5 \%$.

\section{UCAPAN TERIMA KASIH}

Penulis mengucapkan terimakasih yang setinggi-tingginya kepada jurusan Teknik Kimia Institut Teknologi Sepuluh Nopember yang telah banyak memberikan dukungan terhadap pengembangan penelitian ini.

\section{DAFTAR PUSTAKA}

[1] S. Purwono, "Koefisien Perpindahan Massa pada Pemisahan Aspal Buton dari Kabungka dan Bau-Bau dengan Pelarut n-Heksan," Forum Tek., vol. 29, pp. 40-49, 2003.

[2] Aris, "Physical and Chemical Characterization of Oil Sands Observed at Imeri in Ogun State of South Western, Nigeria," Geosci. Eng. Partnersh. J., 1996.

[3] Tommy, "Proses Ekstraksi Asbuton dengan Pelarut Pertasol," Institut Teknologi Sepuluh Nopember, 2012.

[4] S. Shidiq, M. \& Rachmadhani, "Studi Proses Pemisahan Bitumen dari Asbuton Dengan Proses Hot Water Menggunakan Bahan Pelarut Kerosin dan Larutan Surfaktan,” Institut Teknologi Sepuluh Nopember, 2013.

[5] Zindy, "Studi Proses Pemisahan Bitumen dari Asbuton Menggunakan Media Air Panas dengan Penambahan Surfaktan," Institut Teknologi Sepuluh Nopember, 2013.

[6] F. C. Division, "Oil Sand,” 2014. [Online]. Available: hhtp://ems.psu.edu/ pisupati/ACSOutreach/Oil_Sands.html.

[7] D. Akinyemi, LP, "Physical and Chemical Characterization of Oil Sands Observed at Imeri in Ogun State of South Western, Nigeria.," Geosci. Eng. Partnersh. Journal., 2013.

[8] Departemen Pekerjaan Umum ; Direktorat Jenderal Bina Marga, Pemanfaatan Asbuton. 2006.

[9] Q. dan K. H. C. Dai, "Hot Water Extraction Process Mechanism Using Model Oil Sands," Fuel Process. Technol., vol. 75, no. 2, pp. 220-226, 1996.

[10] W. Siswosoebrotho, Bambang Ismanto., Kusnianti, Neni., Tumewu, "Laboratory Evaluation of Lawele Buton Natural Asphalt in Asphalt Concrete Mixture," in Eastern Asia Society for Transportation Studies, 2005, pp. 857 867. 